\title{
EARLY SUCCESSES: EL NIÑO, SOUTHERN OSCILLATION AND SEASONAL FORECASTING
}

\author{
David Anderson \\ Retired to a private address, Email:dlta@btinternet.com
}

\begin{abstract}
Comparison is made between events surrounding the 1982/3 El Niño and the 1997/8 El Niño. The lack of a coherent appreciation of the development in the early stages of the 82/3 El Niño lead to the formation of TOGA, Tropical Ocean Global Atmosphere, a 10 year experiment from 1985 which saw the foundation of a comprehensive observing system for the tropical Pacific that has since expanded to cover the tropical Atlantic and is now being extended to the Indian Ocean. With such an observation array in place providing high quality data, the 97/8 El Niño was well captured. Provided the quality of the data obtained while it was a research array can be maintained now that it has operational status, it is highly unlikely that any El Niño or La Niña could sneak up unobserved. Of course, seasonal prediction is about more than just predicting extreme El Niños. The overall skill spanning the period from 1981 is considered.
\end{abstract}

Considerable progress has been made in ocean analyses. This is partly the development of much more mature models and assimilation schemes but partly because of better quality surface fluxes obtained from atmospheric reanalyses. Seasonal forecast skill has also improved over the last 15 years as coupled atmosphere ocean models and ocean analyses have improved. Observing system experiments are used to show the importance of the TAO/TRITON/PIRATA (Tropical Atmosphere Ocean/Triangle Trans-Ocean Buoy Network/Prediction and Research Moored Array in the Atlantic) mooring system as well as altimetry. It is less easy to show statistically significant impact of the Argo (Array for Real-time Geostrophic Oceanography) data on forecast skill at this stage since the Argo period is quite short compared to that of the variability of ENSO (El Niño/Southern Oscillation).

\section{INTRODUCTION}

To gain some impression of the progress made over the last 25 years or so, it is useful to go back to the early eighties. 1982/3 saw one of the largest El Niños ever recorded, surpassed in only some respects by the El Niño of 1997/8. There was a marked difference in our awareness of El Niño and how to monitor its progress between these two events, however. It is often recorded that not only was the 1982/3 El Niño not forecast, scientists weren't even aware it was happening until it was well developed. That lack of awareness lead key scientists to plan an experiment to observe and understand tropical phenomena so that uncertainty surrounding the 82/3 El Niño would not happen again. That endeavour resulted in a major ten-year experiment, TOGA (Tropical Atmosphere Global Ocean), which kicked off in January 1985. TOGA was one of the most successful international experiments in climate understanding, but, as we will see, it certainly did not solve all the problems. Although the ocean observing system performed well, keeping the world well informed of changes in the Pacific Ocean, including the 1997/8 El Niño, predictions of the severity of this event were generally poor.

El Niño is a coupled phenomenon; it involves knowledge of both what is happening in the ocean as well as in the atmosphere. The atmospheric observing system, (which was developed to permit numerical Weather prediction, rather than Climate prediction) has advanced substantially since the early eighties but more importantly the upper ocean observing system has improved from an opportunistic system to a more mature 'pseudo-operational' system. Measurements of the interface between the atmosphere and ocean have also improved. In the early eighties, it was possible to measure sea surface temperature (SST) from Advanced Very High Resolution Radiometer (AVHRR) satellites and so changes in SST in the equatorial Pacific should have been detected. Unfortunately, it seems the satellite was largely blinded because of aerosol; in late March, early April 1982 there was a series of major eruptions from El Chichón, a volcano located in Mexico at about $17 \mathrm{~N}$. The erupted gasses spread westward, circling the earth in a few weeks. This lead to radiative measurements being outside the acceptable range, and the default setting of climatological sea surface temperature being invoked; no evolving El Niño was seen from space.

Figure 1 shows the analysed SST as from the Climate Diagnostics Bulletin for October 1982. My recollection is that this bulletin was received about two to three months after the analysis date, as time was required to collect the in situ observations from ships, to process the satellite data and to blend the two sets of observations. As there was no web server, the Bulletins were sent by (surface) mail. Therefore, it is not surprising that there should be a delay in identifying the onset of El Niño. 
This was not the only reason for not being aware of what was going on, however. At the time, the conceptual model of El Niño was that SST anomalies started in the east, along the South American coast and spread westwards [1]. In 1982, there was no strong sign of coastal warming, so no El Niño was anticipated. Secondly, sea level was not evolving as expected. One reason was that there had been no "buildup" of sea level in the western Pacific by stronger than normal trade winds prior to 1982, presumed

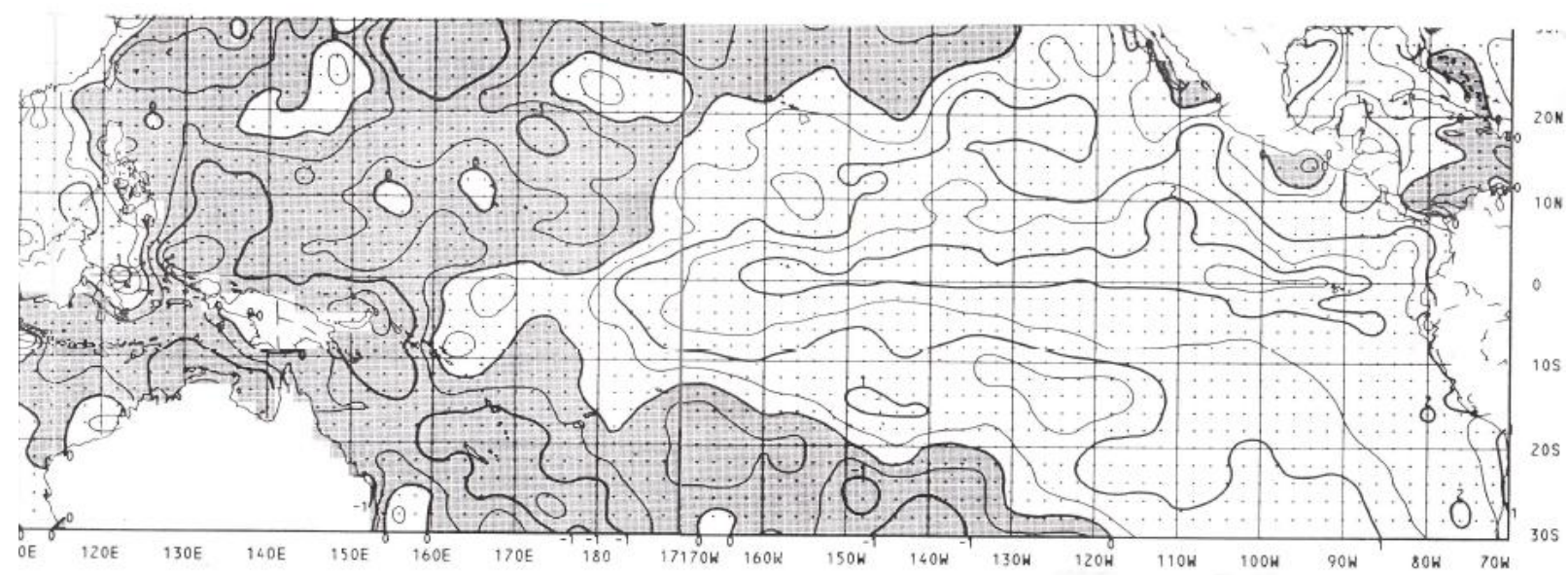

Figure 1. SST as analysed for Oct 1982. From the Climate Analysis Bulletin.

to be a necessary precursor of El Niño [2]. Klaus Wyrtki had played a major role in establishing a network of island tide gauge stations. Strong equatorial trade winds in 1975 increased sea level in the western Pacific. The relaxation of the wind in January 1976 allowed an internal equatorial Kelvin wave to form and proceed eastward, raising sea level along the eastern side of the ocean [3]. However, this did not happen according to plan in 1982/3. In fact, in October 1982 Klaus is quoted as saying 'to call this El Niño would be child abuse' (Moore, personal communication). Therefore, the failure to alert the world to an impending El Niño was really a combination of factors: a major volcanic eruption blinding the satellite observation, El Niño evolving differently to our then understanding of how it should evolve and effectively no real-time observations of the subsurface ocean.

A key observation that lead to an El Niño alert was that made by Toole on board the research ship Conrad which happened to be on the equator and observed that the thermocline was $60 \mathrm{~m}-150 \mathrm{~m}$ deeper than normal; this set the alarm bells ringing. See [4] and [5] for a later analysis of the data.

\section{2, TOGA AND AN IMPROVED OCEAN OBSERVING SYSTEM}

Regardless of the cause, the failure to recognise in a timely fashion what was evolving in the tropical Pacific, lead some important scientists to meet and ponder what should be done. A major observing and understanding programme was proposed though the $\mathrm{CCCO}$ (Committee for Climate Change in the Ocean) and WCRP (World Climate Research Programme) channels, which was formalised in the Tropical Atmosphere
Global Ocean (TOGA) programme. Key objectives of TOGA were:

(1) To gain a description of the tropical oceans and global atmosphere as a time-dependent system in order to determine the extent to which this system is predictable on the timescales of months to years and to understand the mechanisms and processes underlying its predictability.

(2) To study the feasibility of modelling the coupled ocean-atmosphere system for the purpose of predicting its variations on time scales of months to years.

(3) To provide the scientific background for designing an observing and data transmission system for operational prediction if this capability is demonstrated by coupled-atmosphere-ocean models.

To put the state of the observing system in perspective, Fig. 2 shows a snapshot of observations in 1979 and at 10 -year intervals. In the late seventies, early eighties, the observations were mainly from XBTs (Expendable bathythermograph). There were odd research cruises such as that described above but they were not designed to detect changes in a systematic way. XBTs measured only temperature as a function of depth. The data were recorded on ship but only made available after someone met the ship at port, collected the data and then put it on the GTS (Global Telecommunications System) or sent it to a data archive. This usually took a few months. Technology to record the data and transmit it electronically grew slowly in the eighties and nineties to the extent that nowadays, such XBTs as are made would be transmitted rapidly. When viewing Fig. 2, recall that, 
especially in the early years, much of the data illustrated would not have been available in real-time.
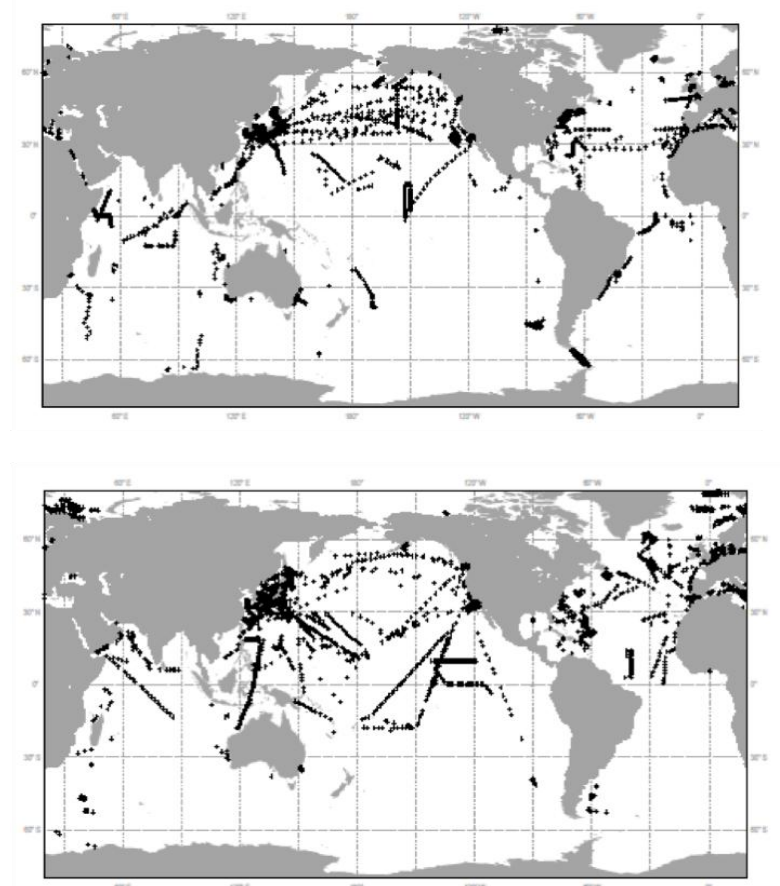

The first task of TOGA was to develop the XBT network in the Pacific. This had already begun prior to
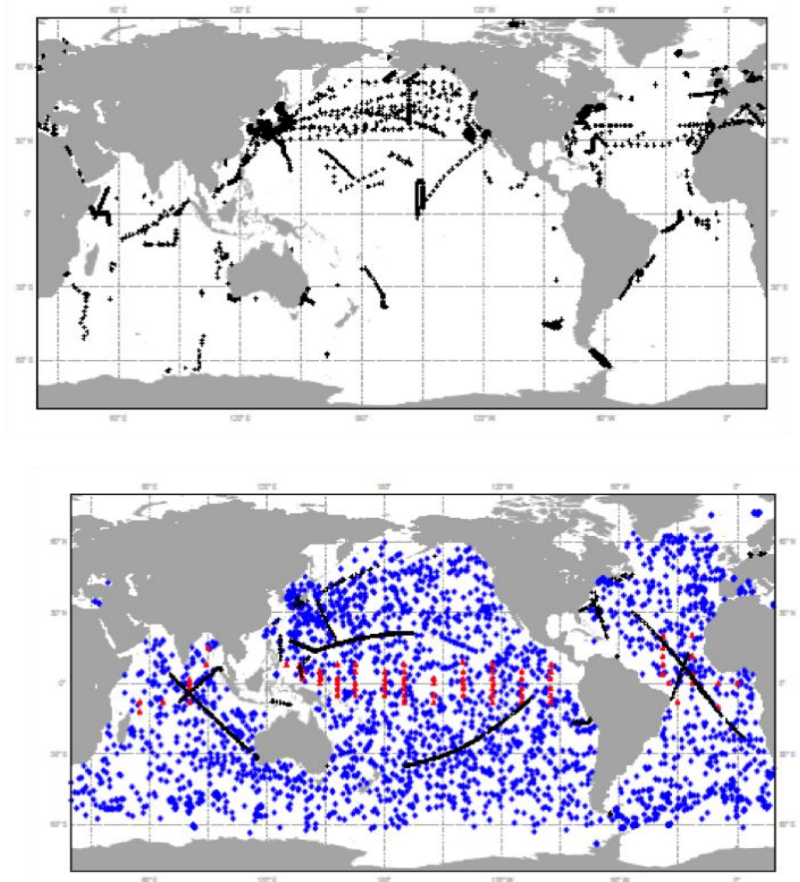

Figure 2. Data coverage at roughly 10 year intervals for 10-day periods centered on a) 16 April 1979, b) 23 April 1989, c) 21 April 1999, d) 18 April 2009. The data shown are those entering the ECMWF reanalysis system ORA3, based on data collected as part of the ENACT and ENSEMBLES project [6]. Remember however that much of the data would not have been available in near-real-time in the earlier years.

the formal start of TOGA through the Pacific Panel of the CCCO. The technology existed; what was required was an expanded network of ships of opportunity (largely merchant ships). This relied on a network of volunteers, to apply for funding to set up arrangements with ship operators, to train ship crew to load and fire the XBT, to make and record the data. While this was fine as an interim measure, it was not the way of the future, not least because the ships were merchant ships, which took the most efficient route between ports. The coverage therefore reflected the major shipping routes, not necessarily the important oceanographic areas.

Fortunately, technology to deploy fixed moorings, to leave them in the water for months and later recover them was also evolving, largely as a result of David Halpern and Stan Hayes at PMEL (Pacific Marine Environmental Laboratory). Halpern had developed the technology to deploy moorings in the high velocity regions of the equatorial ocean in up to $6000 \mathrm{~m}$ depths. [7]. These taught-wire surface moorings could remain in the water for many months making both thermal and current measurements. Hayes was heavily involved in the TOGA programme, which called for the collection and rapid delivery of measurements of the thermal and near-surface winds across the whole Pacific within a few degrees of the equator. The mooring system had to be relatively low cost so they could be deployed in relatively large numbers across the vast expanse of the Pacific basin. Hayes, in collaboration with Ed Harrison proposed a network of $\sim 70$ moorings. One of his last papers before his untimely death in 1992 [8], gives an excellent description of the state of the array in 1990 when some 19 buoys had been deployed and many more planned [9]. This paper also describes the proposed final array. Although Hayes did not see the completion of his dream, responsibility for the array fell to Mike McPhaden who brought the array to maturity by the end of TOGA [10].

The ATLAS moorings (Autonomous Temperature Line Acquisition System) typically record temperatures at 10 depths in the upper $500 \mathrm{~m}$, as well as surface temperature at $1 \mathrm{~m}$ and surface wind, air temperature, and humidity at a height of $4 \mathrm{~m}$. This has been a wonderful example of how to measure key variables in the upper $500 \mathrm{~m}$ of the ocean. I still find it impressive that I can sit at home and see, on a more or less realtime basis, what is happening in the equatorial Pacific, one of the remotest places on earth.

One of the great visionaries of TOGA and the first Chairman of the Scientific Steering Committee was 
Adrian Gill, author of that great book AtmosphereOcean Dynamics [11]. It is very sad that he died so soon after TOGA started and never saw what a wonderful experiment he had conceived and initiated. TOGA was innovative not just in developing the observation array but also in the change it brought in data exchange. All data collected through TOGA funding had to be made freely and rapidly available. This was similar to the meteorological approach but very different to the then current oceanographic practice whereby data were only released after the collector had finished analysing and publishing on them.

One of the objectives of TOGA was to provide prediction capability if it proved possible. Early studies such as those of [12], Philander, McCreary and Anderson had shown some skill in representing low frequency variability reminiscent of El Niño. In fact, the [13] study had also indicated eastward progression of SST in contrast to the canonical El Niño, which progressed westward. The study by [14] indicated predictability of El Niño and had the positive effect of kick starting seasonal ENSO (El Niño Southern Oscillation) prediction. In the early days, only one forecast was made per month. The models were largely deterministic, with the atmosphere slave to the ocean; once the SST was known there was only one large-scale atmospheric state linked to that SST pattern.

Tim Palmer had emphasised that really, there were many atmospheric states associated with a given SST, and dealing with this had been a major part of the PROVOST ((PRediction Of climate Variations On Seasonal Timescales) project. See the special issue of Quarterly Journal of the Royal Meteorological Society 2000, dealing with PROVOST/DSP (Dynamical Seasonal Prediction). In the nineties, the field had matured to the state where ENSO forecasts could be made using full general circulation models of both the atmosphere and ocean. (There were also hybrid models where one component was a GCM and the other was a model of reduced complexity but we will not dwell on these. The reader is referred to the special issue of JGR recording the successes of TOGA, for several papers dealing with ENSO theory; modelling and predictionsee [15]

\section{DEVELOPMENT OF A COMPREHENSIVE SEASONAL FORECASTING SYSTEM}

After the early days of using simplified models, my experience is mainly with the fully coupled GCM

\section{El Niño 1997/98 Seasonal Predictions}

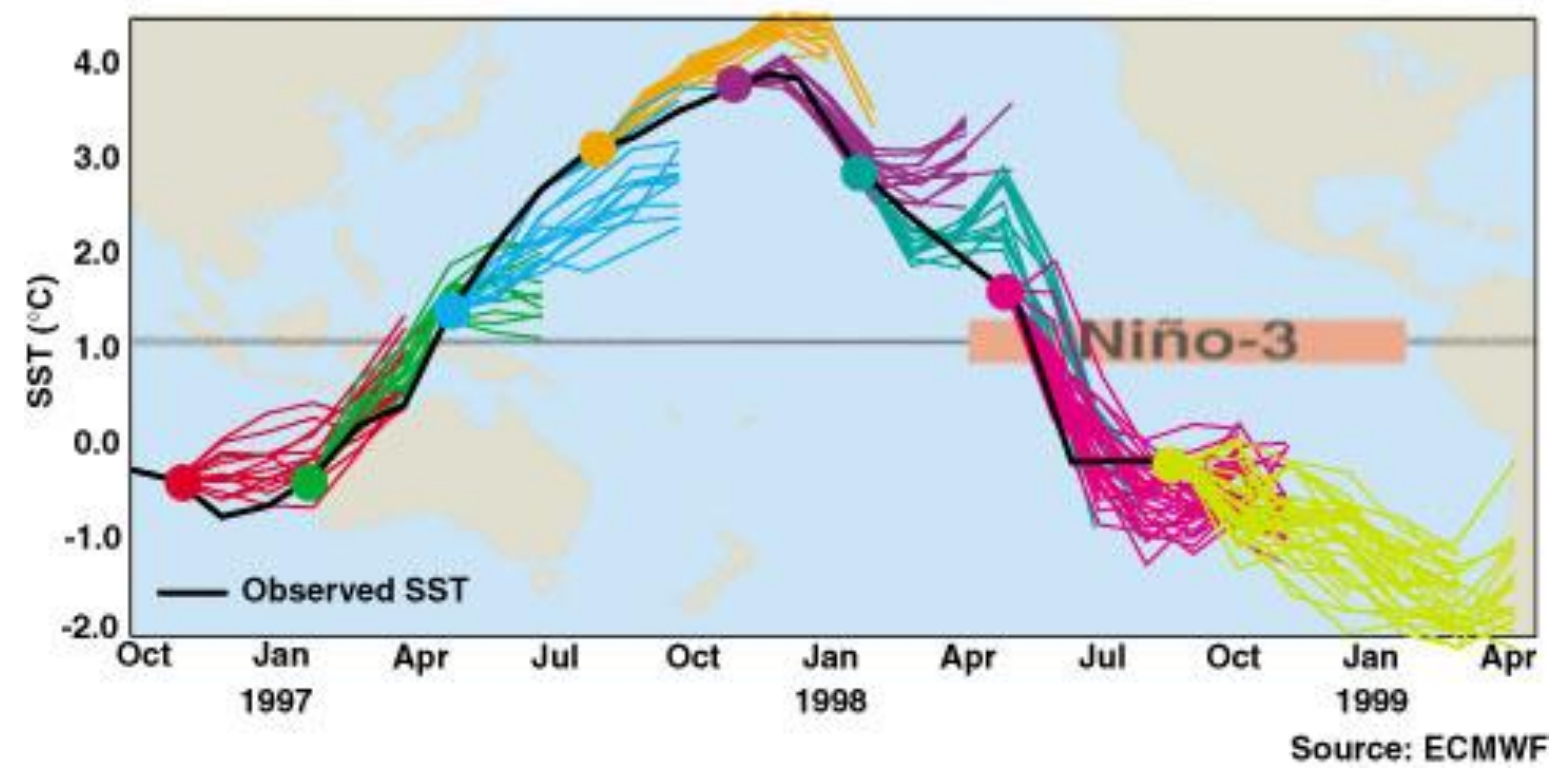

Figure 3. Predictions for the 1997/8 El Niño. Different colours indicate different start months. The various ensemble members for a given month have slightly different initial conditions. The forecasts were 6 months long. This figure was produced by CLIVAR based on data from the ECMWF S1 seasonal forecast system.

models developed at ECMWF (European Centre for Medium-Range Weather Forecasts) and so I will present results from the models I am most familiar with. Some similar experience could be developed based on other 'semi-operational' models developed at NOAA/NCEP (National Oceanic and Atmospheric Administration/National Centers for Environmental Prediction) or the Met Office [16] and [17]. 
The first seasonal forecast system at ECMWF (imaginatively called System 1 or S1) was developed in 1996. This was running routinely but the results were not made public as the system's skill was still being assessed. However, the forecasts for Niño3 were showing the development of a large positive anomaly in 1997 and the Council of ECMWF felt this information should be made publicly available. Within a couple of weeks of the Council decision, the results were on the web. Figure 3 drafted by CLIVAR (Climate Variability and Predictability) but based on the ECMWF results, shows forecasts from various starting months. Several different starting conditions were generated by perturbing the SST [18]. Different start months are shown in different colours. The solid black line indicates the subsequently observed SST. The overall impression is that seasonal forecasting is a great success. However, if you look carefully you will see that the forecasts initiated in the spring of 1997 seriously under predict the intensity of the El Niño. This is more obvious if you consider additional start months

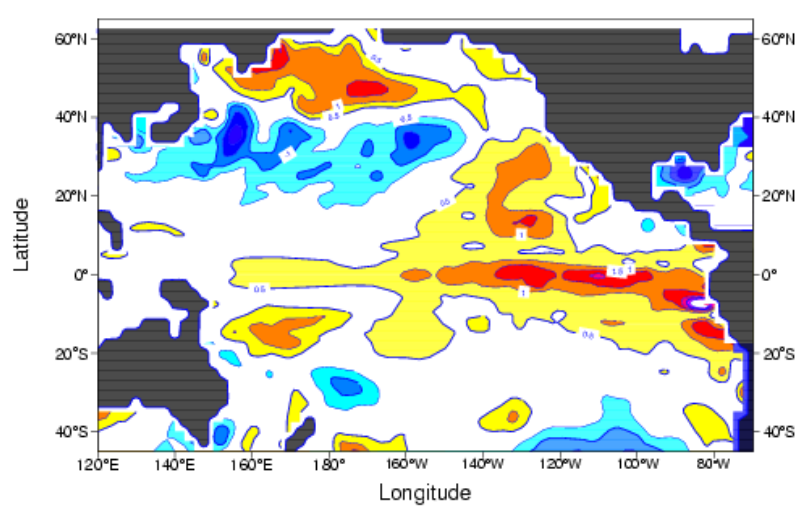

to those shown as illustrated in [19]. In the mid nineties, it was only possible to run a few ensemble members and even more serious, the system could only be tested on a few past cases, because of computer limitations. In the Niño regions, it is usually only necessary to run a few ensemble members but one would like to span as many years as possible. Although it is possible to generate many forecast realisations (i.e. ensemble members), there is only ever one realisation of truth, and so one needs to span as many years as possible to get a good assessment of how well one can predict 'truth'. If one wants to assess the skill in predicting events away from the equatorial region, the ensemble size needs to be larger as the width of the forecast pdf is wider and the shift smaller.

Figure 4 is an interesting example of two forecasts of the 1997 El Niño. It shows the SST forecast from two different initial conditions, differing only in small perturbations to the SST- smaller than any likely measurement error. Yet after a few months, largely

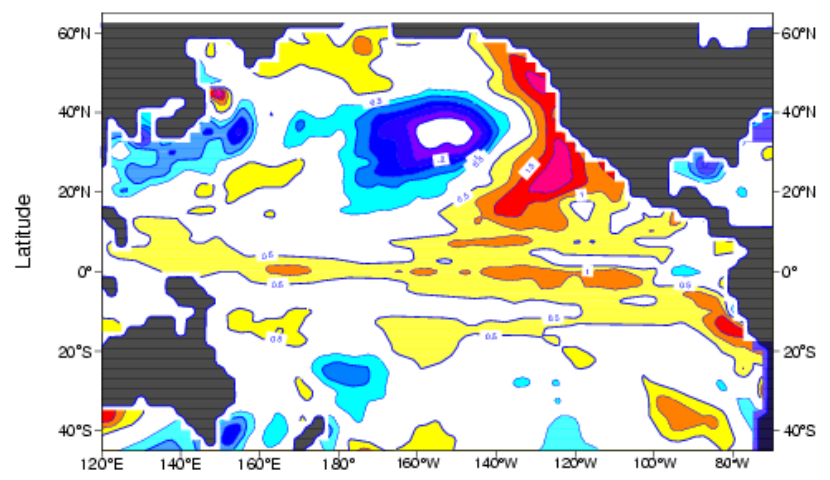

Figure 4. SST anomalies for May 1997 from forecasts initiated in Dec 1996. The initial conditions differ by having slightly different SSTs, the perturbations applied being $\sim 0.01 \mathrm{~K}$.

through the chaotic nature of the atmosphere and by association the ocean, the differences are larger than you might think. Both ensemble members predicted El Niño but the details differ significantly, especially in the mid latitudes. If the level of variability in this model is correct, this figure shows that we will never be able to predict the details of El Niño; there will always be a substantial uncertainty resulting from chaotic processes over which we have no control. Of course, this figure could exaggerate the extent of chaotic processes if the model is too active but it could also underestimate their role if the model is not sufficiently active. We do not know how active S1 really is. On the one hand it appears to be over-active when we compare the range of ENSO variability it predicts while, on the other hand, it under-represents the MJO or intraseasonal variability.

\subsection{Progress over the years.}

It is almost 14 years since the development of the first ECMWF seasonal forecast system. Currently forecasts are made with the third system (S3) introduced operationally in early 2007, though it was running and tested in 2006 (20). Have we made progress over these 14 years? The first thing to note is that the typical lifetime of a system is about 4 to 5 years. This is in marked contrast to operational weather forecasts where model updates are made every few months. Why the different philosophy? All models have systematic errors. In extended range forecasting, such as seasonal forecasting, it is necessary to deal with this error. One strategy, initially proposed by Klaus Hasselmann and used extensively in long climate integrations for a number of years is flux correction. It was seen as 
progress when models improved to the extent that they could be run without flux correction [21], but in recent times flux correction has reappeared as the perturbed physics strategy of developing an ensemble of climate integrations has been developed [22].
At ECMWF, in 1996, we decided not to go down the flux-correction route; part of the rational for developing seasonal forecasts was to expose model weaknesses and so lead, hopefully, to model improvements and better medium range forecasts. The strategy to deal with model error that was adopted was to run many

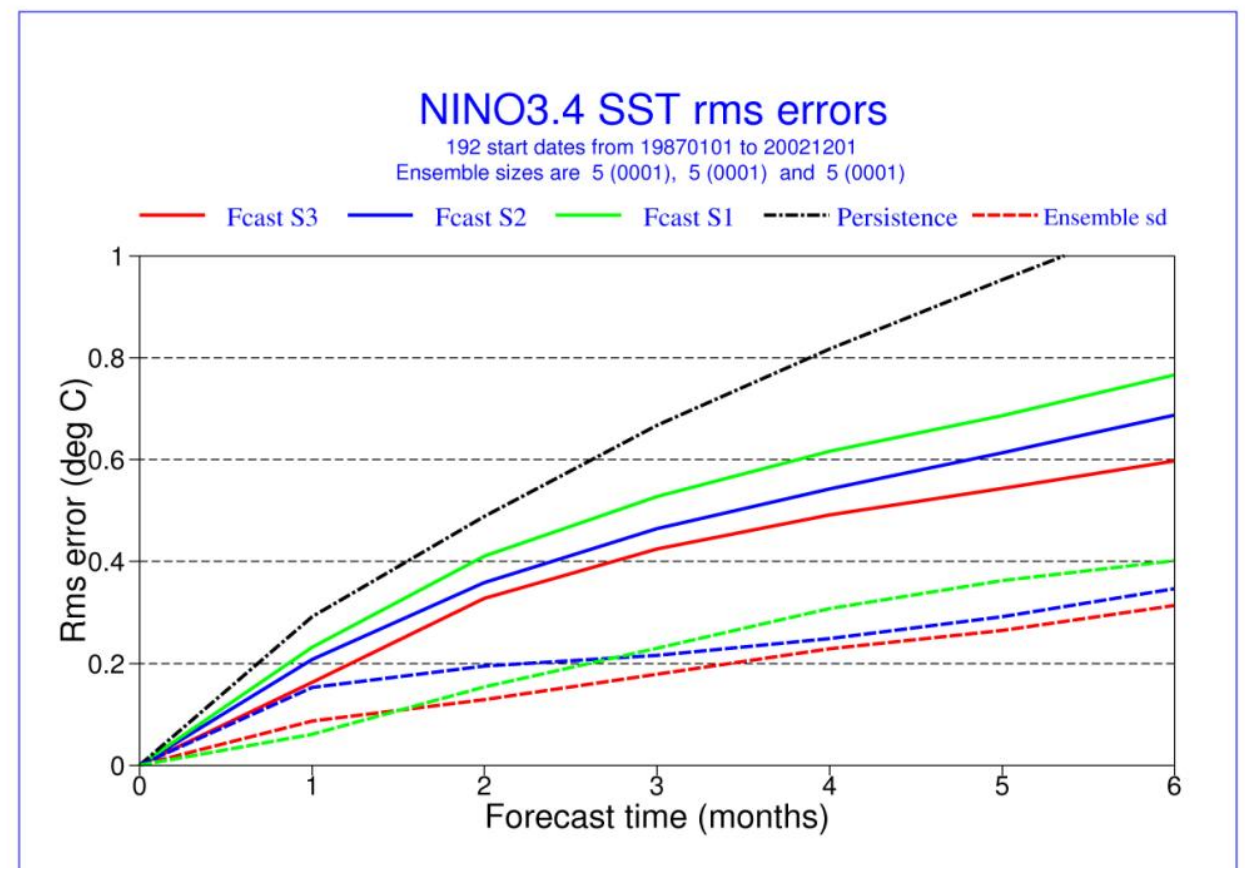

Figure 5. Forecast error growth for the Niño3.4 region for S1, S2 and S3. The error growth for S3 is substantially lower than for $S 2$ which in turn is less than S1, indicating steady progress in improving seasonal forecasts, either through model improvement or through better assimilation techniques. Part of the improvement could come from improving observations, since the data set used is more comprehensive in S3 than in S1-S3 used the ENACT (ENhAnced ocean data assimilation and ClimaTe prediction) data set which was not available at the time of S1.

realisations of the model over past events in order to define the model climatology. Forecast anomalies could then be obtained by comparing a forecast ensemble against the model climatology. This requires the model forecast errors to be evaluated for each start month for every month of the forecast. Initially forecasts were for 6 months, subsequently increased to 7 months and recently (in S3), the forecast range was increased further to 13 months. The correction strategy makes only a linear correction; where the correction is really nonlinear then the strategy might not work well. Experience is that is has worked rather better than was expected [23] and[24]. An interesting spin-off is that this strategy is now being used in medium range and monthly forecasting [25].

To assess the improvement in skill over the three systems we will consider the growth of error in the forecast period. This is shown in Fig. 5 for the NIÑO3.4 region. For comparison, the skill of using persistence is also shown. The results span the period 1987-2002. This is considerably less than the period spanned by $\mathrm{S} 3$ (1982-2009), but is the longest common period for the three systems. This figure clearly shows the reduction in error in S3 compared with S2, which in turn was considerably better than $\mathrm{S} 1$ in terms of growth of forecast error. Also shown in the lower three curves is the spread of the ensemble. This can be considered as a measure of predictability, the best we can achieve, if the model and initial conditions were essentially perfect. One can think of this as the error one would obtain if one took an ensemble member as truth and measured the difference of other ensemble member from this truth as error. The difference or growth of error is that which results from chaotic i.e. unpredictable processes. 


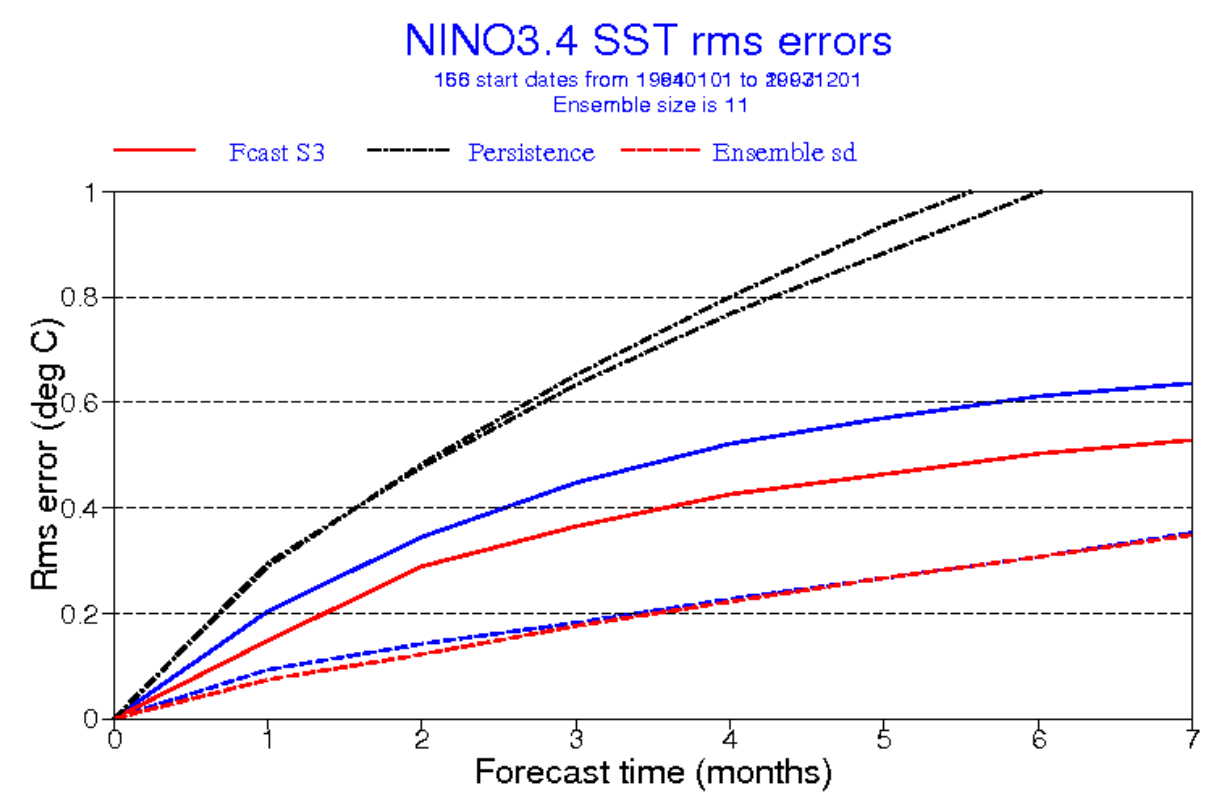

Figure 6. Forecast error growth for the Niño3.4 region for S3, for the forecast periods 1982-1993 and 1994-2006. The reduced error growth in the later period is likely to result from a better ocean observing system, although if the atmospheric observing system improved in this period that too could contribute to the lower error growth. From [24].

Clearly, there is a marked difference between the three estimates of perfect forecast error and that, which is currently achieved. This is good news since it implies that as the models get better and we can create improved initial conditions, primarily ocean initial conditions the error in the forecasts will be much smaller than it is currently. There is a smaller difference in the predictability limits of the three systems. Some difference is to be expected since they are model estimates and as the properties of the model change, so too can the estimates of predictability. On the other hand, the estimates do not differ very much which suggests the estimates may be fairly stable and realistic. A figure such as this does not tell the whole story, however. S1 was much more active i.e. it forecast larger SST anomalies than S2 or S3. In fact, it was overactive in that the anomalies on average were larger than observed anomalies whereas S2 was underactive. S3 is also on the underactive side though not as strongly so as S2 [24]. This figure has another interpretation, however; that the forecast system is too confident. The growth of error in reality is larger than it is estimated to be i.e. the system is too confident in its forecast probabilities. This can be offset to some degree by the use of multimodel forecasts. See EUROSIP, ECMWF web site, or [26] and other papers in that book.

\section{THE IMPORTANCE OF OCEAN DATA}

As shown earlier, there has been a substantial improvement in the observation of the ocean, primarily as a result of TOGA and its successor CLIVAR, for the tropical region, and a result of WOCE and altimetry and more recently Argo (Array for Real-time Geostrophic Oceanography), (for the global ocean. There was a major improvement about 1993 when the TAO array was reaching maturity and about that time, high quality altimetry came on stream with the launch of TOPEX/POSEIDON. Did these observational improvements lead to an improvement in forecast skill? [24] show that there is pretty strong evidence that they did. Fig. 6 shows that rms error in NIÑO3.4 in the pre 1993 period is considerably higher than in the post 1993 period. Also shown are the ensemble spread and the skill of persistence. Neither of these shows a marked difference, suggesting that the reduced error is not related to a different level of inherent predictability but to an improvement in the system. The same model and the same ocean analysis system are used throughout (S3). Therefore, they conclude that the improvement in forecast skill is from having a better observing system. Another way of assessing forecast skill is by performing OSEs (Observing System Experiments). An extensive 
set of experiments was carried out by [27]. Results are summarised in Fig. 7. The period considered is from 1993 to 2006, the period in which there is both altimetry and TAO mooring data. First, a set of hindcasts (sometimes now called reforecasts) was made in which ocean initial conditions were obtained by forcing the ocean with the fluxes from ERA40 up to the end point of ERA40. Subsequent to that, the forcing came from the ECMWF atmospheric operational forecast system. All available ocean data were assimilated in an ocean reanalysis using data from ENACT (ENhAnced ocean data assimilation and ClimaTe prediction)/ENSEMBLES data set [6]. This is the control set of initial conditions. Another ocean analysis was performed, removing only the TAO data and a third in which only the altimeter data were withheld. A series of hindcasts was then made for each of these analyses.

In Fig. 7, the impact of these two data-withholding experiments is shown for various regions. The impact of withholding moorings is largest in the equatorial Pacific, as expected. There is an impact elsewhere as

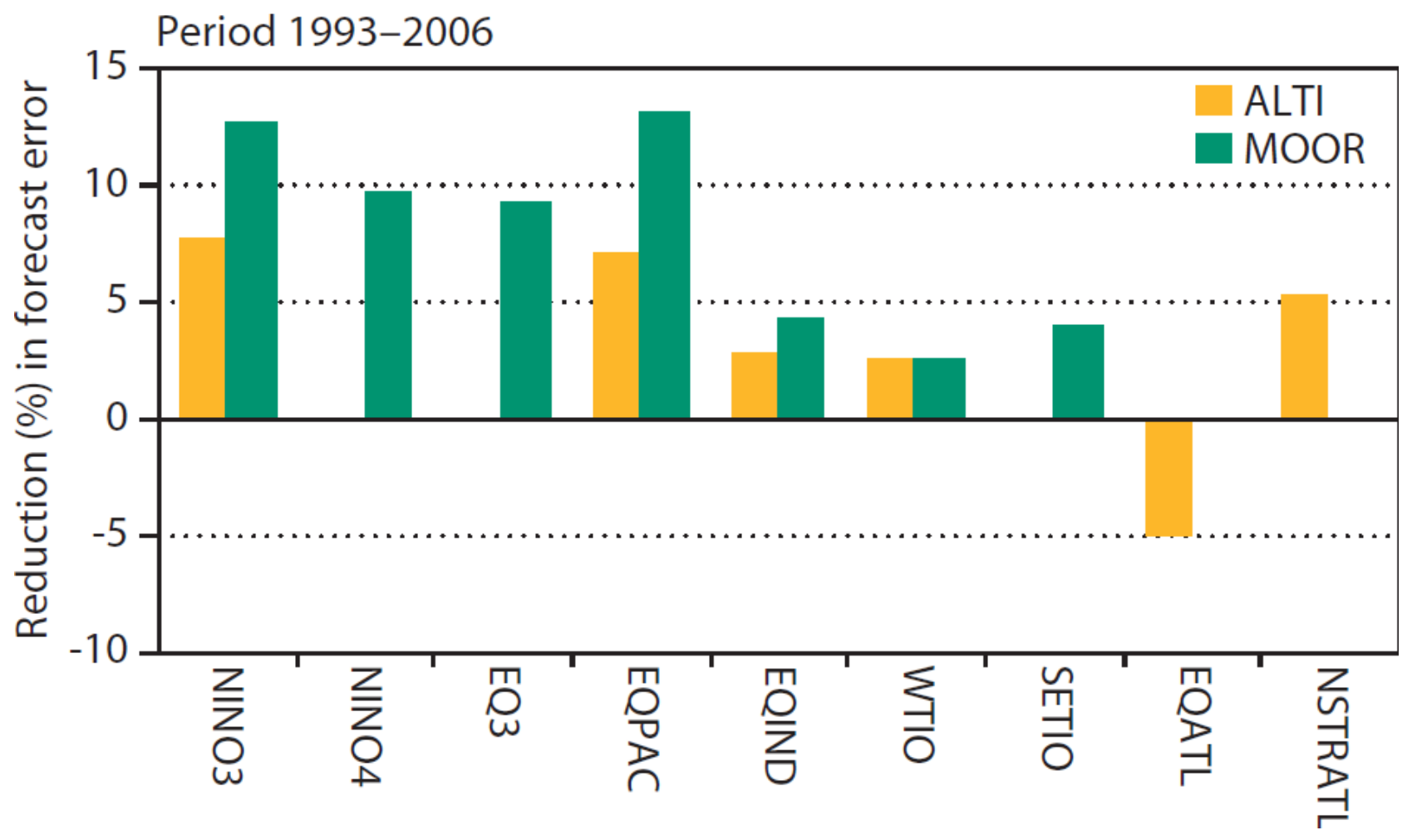

Figure 7. Impact of different components of the observing system, as measured by the reduction in mean absolute error for the forecast range up to 7 months. The impact of withdrawing altimeter data and mooring data for the period $1993-$ 2006 is shown. ALTI shows the difference in skill between a full system and one in which there are no altimeter, while MOOR indicates the difference in skill between a full system and one in which moorings have been withheld. From [27].

there are moorings in the Atlantic and the Indian Ocean and remote effects or teleconnections could also play a role. Altimetry also has a significant impact even in the tropical Pacific. The effect of withholding both TAO moorings and altimetry has not been considered but the effect of withholding TAO, altimetry and XBT has been assessed [28]. One can further refine the impact of observations by looking at the impact of Argo but this is statistically less significant as the Argo period is only a few years. An interesting feature of Fig. 7 and several others in the Balmaseda and Anderson study is the counterintuitive result in the equatorial Atlantic. Assimilating ocean observations actually makes the forecasts worse. The tropical Atlantic is a difficult region to get right. [28] pointed this out several years ago and the study by [29] gives a more specific analysis. Clearly, the negative impact indicates problems either with the model or with the assimilation procedure in this area where model error is large.

\section{REANALYSES}

One of the great successes of the last 20 years has been the availability of reanalyses. In the atmospheric context, reanalysis is a big task needing many manyears of effort. Originally carried out only at NCEP and ECMWF, other groups are now reanalysing at least part of the record. I will just consider the ECMWF reanalysis ERA40 [30]. This was meant to be a 
reanalysis of 40 years. In the event, it covered the slightly longer period 1958-2002. The philosophy behind reanalysis is that models and data assimilation processes have improved over the years and so we are in a much better position to make use of data than we were at the time the data were taken. In addition, a substantial effort was put into recovering data taken at the time but not passed to operational centres. So, in fact there are more data in the reanalyses than went into the analyses made at the time. Satellite data may also have been reprocessed to give more accurate measurements. A further rational for reanalysis is that the same system is used throughout, so spurious variability is not introduced by changes in the model/analysis system (though spurious sources of variability can be introduced by changes in the observing system.) See also [31].

Atmospheric reanalysis is important for seasonal forecasting in that it gives improved atmospheric initial conditions from which to start seasonal integrations, but perhaps more importantly it provides improved forcing fields for driving the ocean. Ocean data are sparse, even in recent times, so the forcing of the ocean is important in establishing the ocean state, especially in the tropical regions.

Several groups have produced ocean reanalyses. The volume of data available in the early years hardly
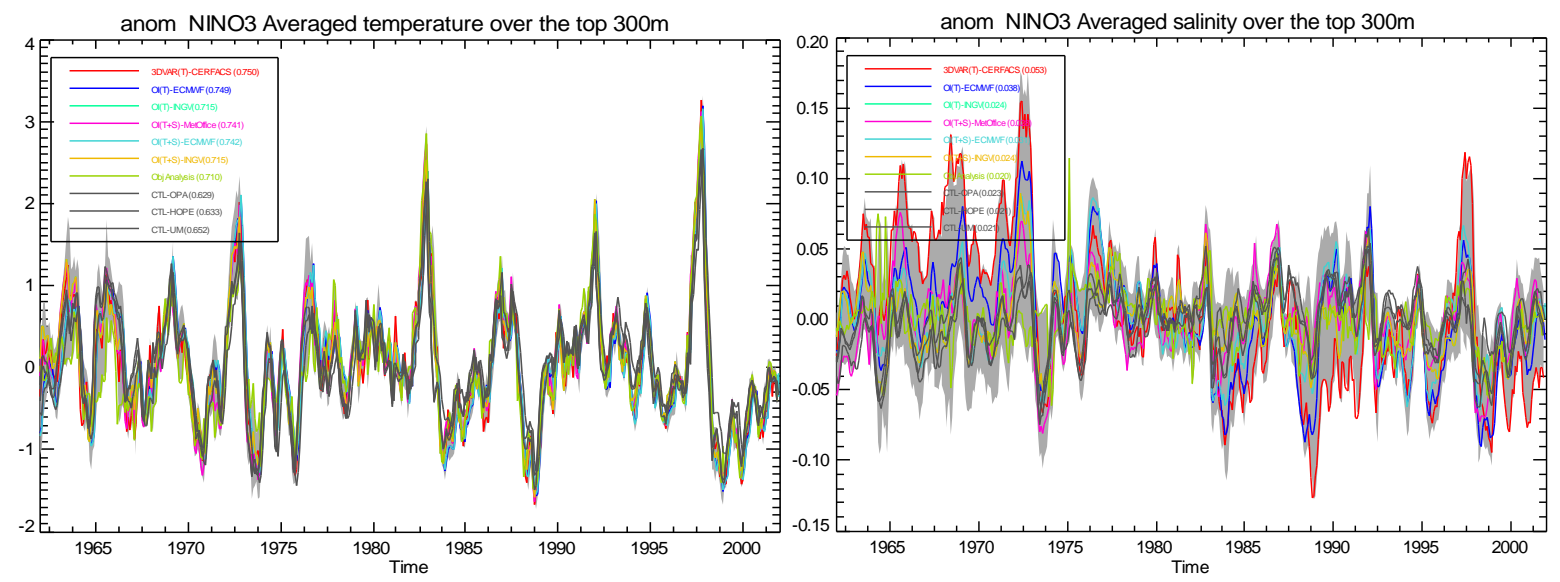

Figure 8. Reanalyses of a) sea surface temperature and b) sea surface salinity in the Niño3 region from several different ocean reanalyses. See presentation by Balmaseda on the CLIVAR GSOP web site [32], Reading meeting report, 2006. Although there is a colour code linking analyses to plots, you are not expected to read it. The purpose of the figure is to show the range of variability in the different analyses

warrants a model resolution greater than 1 degree. Running a model at this resolution is cheap and fast and a reanalysis for 50 years can be produced in a matter of a month, half that if one is prepared to split the analysis into say two chunks of 25 years, which can then be run in parallel. As a result many ocean reanalyses have been performed. The quality of these reanalyses varies however; some analyse salinity data, some not, some use altimetry, some not, some correct for model bias, some not, some preserve the T-S relationship, some not and so on. Figure 8 shows the analysis of surface temperature and salinity from a number of analyses. For display purposes, we show only the values in Niño3. One might expect SST to be reasonably tightly constrained and indeed that is what Fig. 8a shows. However, the interanalysis differences in surface salinity (panel b) are as large as the interannual variability. As model strategies for assimilating data and atmospheric analyses improve, especially with respect to precipitation and surface wind, one might expect the interanalysis differences to reduce with time. However, salinity has been undersampled in the past and so it is unlikely that all the spurious variability will be removed. If one looks at other variables such as the strength of the meridional overturning circulation important for decadal prediction, the position is even more depressing and less likely to be resolved/reduced substantially. See the web site associated with the CLIVAR Global Synthesis and Observation Panel (GSOP), chaired by Detlef Stammer, which is very much concerned with the development, and assessment of ocean reanalyses. See also [33] or [34]. At the time of development and operational implementation of S2, the only atmospheric reanalysis available was ERA15 (FifteenYear European Re-Analysis project), a 15-year reanalysis for the years Dec 1978 to Feb 1994. Atmospheric analyses post Feb 1994 came from the ECMWF operational analysis system, which differed substantially from the analysis system used in ERA15. In particular, there were substantial differences in the quality of the surface wind. Such changes introduce low frequency variability into the atmospheric analyses and consequently into the ocean analyses. As part of 
the EU project DEMETER (Detection of ElectroMagnetic Emissions Transmitted from Earthquake Regions) a series of hindcasts was later run using essentially the same coupled model as for S2 but now using ocean analyses obtained through forcing with ERA40. Two other analyses in which no data were assimilated, but the surface forcing came from either ERA15/OPS or ERA40/OPS were also performed. This study showed that using improved atmospheric forcing fields from ERA40 without assimilating any ocean data were much better than using ERA15 without ocean data and in fact yielded almost as good forecasts as S2, which assimilated ocean data but used ERA15. In other words, the impact of using ERA40 as opposed to ERA15 is as important as assimilating ocean data, at least for S2. The message from these experiments is that one should use the best atmospheric analysis available, as well as assimilating as much ocean data as possible in the best possible way.

\section{SUMMARY AND CONCLUSIONS}

There has been substantial progress over the years in seasonal climate prediction, some of it coming from model development, some from better use of the data and some from greater observation coverage.

We should never again fail to detect El Niño as happened in 1982. Considerable effort has recently been devoted to assessing the potential for making even longer forecasts typically out to a decade [35] and [34]. Although we now have a fair idea of what to look out for in the tropical regions associated with ENSO we do not have the same level of understanding of processes involved in decadal variability, and it is not clear that key signals of impending decadal variability could not be missed. Better observations in the North Atlantic, such as those made by RAPID_WATCH should help but better understanding of key processes is still needed, supported by better models to identify key regions and processes. See also [36].

Meteorological experience suggests that, as models and data assimilation systems improve, greater information can be extracted from past observations. But if key observations are not made, we cannot go back to recreate them. Better to have some redundancy than a deficit. Indeed, without some redundancy it is not possible to evaluate the accuracy of a component of the observing system.

There are several ocean reanalyses made by different groups using different models or assimilation procedures. Most use either ERA40 or the NCEP reanalysis to force the ocean model.

Ocean analyses are currently 'all over the place' with respect to some variables, at least in part because there are insufficient data to constrain the analysis. If the region or variable is not key, then that is not necessarily a problem but if it is, then it is a big concern. Ignorance is still a major challenge as we do not know all the key regions or processes when we extend forecasts beyond seasonal. As atmospheric reanalyses improve- let us hope there will be another longer and better reanalysis at ECMWF or elsewhereocean reanalyses should also improve somewhat.

Although the focus of this talk has been on the equatorial Pacific and ENSO, there is skill in the ECMWF System 3 in forecasting climate variability in the Indian Ocean. The Indian Ocean dipole [37] and [38] is a major mode of variability there, partly linked to ENSO, partly independent of ENSO. Since the author is not convinced that the dipole is greater than the sum of the parts, the skill of predicting the east and western Indian Ocean should be considered separately. The skill is discussed in [24]. There is some skill in predicting Atlantic variability but the forecast horizon is considerably shorter. This could be because the inherent predictability horizon is really shorter or because the models are poor in this region.

Considerable emphasis in this paper has been on predicting SSTs, and mainly in the equatorial region. However, in the end, the value of the forecasts will be judged by their skill over land. The ability to predict land temperature or precipitation over land is lower than over the ocean because they are more chaotic variables. For some users the level of skill will not be high enough to be useful; the ability to predict that the last two weeks of August will be dry and sunny in location $\mathrm{X}$ but wet and rainy in location $\mathrm{Y}$ several months ahead with sufficient confidence to allow a punter to book his holiday months ahead is not feasible, especially if $\mathrm{X}$ and $\mathrm{Y}$ are located in middle latitudes. Nonetheless, we might be able to say something, which is useful for some users of forecasts. How useful a forecast is depends on the use to which it will be put. This is a field in its infancy. Ideally, it requires the development of an application model, which can take the meteorological output and convert it into the application product. The application model can be imbedded in the forecast system. Space does not allow further discussion here but the reader is referred to [39] for an example of malaria prediction on seasonal timescales and to [40] for an application to the Ganges on various timescales. The economic value of forecasts is considered by [41].

It is possible that the strategy of analysing the state of the atmosphere separately from the analysis of the ocean is not the best way forward. This strategy certainly introduces a shock at the start of the forecast but it in not clear that a better strategy currently exists. One possibility would be to analyse the state of the coupled system but no operational system is close to doing this yet. One fundamental difficulty is that the timescales in the atmosphere are short compared with 
the important timescales in the ocean. Several groups are beginning to address this issue, however, and some assessment of the potential advantages should emerge in the next few years.

\section{ACKNOWLEDGEMENTS}

I thank my colleagues at ECMWF for providing me with figures, and Dennis Moore and Mike McPhaden for interesting reminiscences about the 82/3 El Niño.

\section{REFERENCES}

1. Rasmusson, E.M. \& Carpenter, T.H. 1982: Variations in tropical sea surface temperature and surface wind fields associated with the Southern Oscillation /El Niño. Mon Weather Rev.

2. Wyrtki, K 1975: El Niño-The Dynamic Response of the Equatorial Pacific Ocean to Atmospheric Forcing. $J$ Phys Ocean, 5, 572-584.

3. Wyrtki K. 1979: The response of the sea surface topography to the 1976 El Niño. J Phys Ocean, 9, 1223-1231.

4. Toole, J. M., \& Borges, M. D. 1984. Observations of horizontal velocities and vertical displacements in the equatorial Pacific Ocean associated with the early stages of the 1982--83 El Niño. Journal of Physical Oceanography, 14, 948--959.

5. Toole, J. M. 1985. Near equatorial CTD observations at 85W in October 1982. Journal of Geophysical Research, 90, 929--933.

6. Ingleby, B \& Huddleston, M. 2007: Quality control of ocean temperature and salinity profiles-historical and real-time data. J Mar Sys, 65, 158-175.

7. Halpern, D. 1987: Observations of annual and El Niño thermal flow variations at $0,110 \mathrm{~W}$ and $0,95 \mathrm{~W}$ during 1980-1985. J Geophys Res 92, 8197-8212.

8. Taft, B. \& Wallace, M. 1996: "Stanley P. Hayes, 1944 1992: A Eulogy". J. Climate, 9, 2955-2957.

9. Hayes, S.P., Mangum, L.J. Picaut, J, Sumi, A \& K.Takeuchi 1991: TOGA-TAO: A moored Array for Real-time Measurements in the Tropical Pacific Ocean. BAMS, 72, 339-347.

10. McPhaden, M.J., A.J. Busalacchi, R. Cheney, J.R. Donguy, K.S. Gage, D. Halpern, M. J.I., P. Julian, G. Meyers, G.T. Mitchum, P.P. Niiler, J. Picaut, R.W. Reynolds, N. Smith \& K. Takeuchi, 1998: The Tropical Ocean-Global Atmosphere (TOGA) observing system: A decade of progress. J. Geophys. Res., 103, 14,16914,240 .

11. Gill, A. E. 1982 Atmosphere-Ocean Dynamics Academic Press $662 \mathrm{p}$.

12. Cane, M.A. \& Zebiak, S. 1985: A theory for El Niño and the Southern Oscillation. Science, 228, 4703, 1085-7.
13. Anderson, D.L.T. \& McCreary, J.P. 1985: Slowly propagating disturbances in a coupled oceanatmosphere model, Journal of the Atmospheric Sciences, 42, 615-29.

14. Cane, M.A., Zebiak, S.E. \& Dolan, S.C. 1986: Experimental forecasts of El Niño. Nature, 321, 827832.

15. Anderson DLT, Rothstein, L., Sarachik E., Webster, P. 1998: Journal of Geophysical Research (Atmospheres \& Oceans). Special TOGA Decade Edition.

16. Saha, S., S. Nadiga, C. Thiaw, J. Wang, W. Wang, Q. Zhang, H.M. Van den Dool, H.L. Pan, S. Moorthi, D. Behringer, D. Stokes, M. Peña, S. Lord, G. White, W. Ebisuzaki, P. Peng \& P. Xie, 2006: The NCEP Climate Forecast System. J. Climate, 19, 3483-3517.

17. Graham, R., M. Gordon, P.J. McLean, S. Ineson, M.R. Huddleston, M.K. Davey, A. Brookshaw \& R.T.H. Barnes 2005: A performance comparison of coupled and uncoupled versions of the Met Office seasonal prediction general circulation model. Tellus, 57A, 320339.

18. Stockdale, T., Anderson, DLT, Alves, J. \& Balmaseda M. 1998: Global seasonal forecasts using a coupled atmosphere-ocean model. Nature 392, 370-373.

19. Vitart, Frederic, Alonso Balmaseda, Magdalena, Ferranti, Laura \& Anderson, David 2003: Westerly Wind Events and the 1997/98 El Niño Event in the ECMWF Seasonal Forecasting System: A Case Study Journal of Climate, 16, 3153-3170.

20. Anderson, D., Stockdale, T., Balmaseda, M., Ferranti, L., Vitart, F., Molteni, F., Doblas- Reyes, F., Mogenson K. \& Vidard, A. 2007: Development of the ECMWF seasonal forecast System 3. ECMWF TEchnical Memoranda 503

21. Gordon C, Cooper C, Senior CA, Banks HT, Gregory JM, Johns TC, Mitchell JFB, Wood RA (2000) The simulation of SST, seaice extents and ocean heat transports in a version of the HadleyCentre coupled model without flux adjustments. Clim Dyn 16:147168.

22. Stainforth, D. A. \& 15 others 2005: Uncertainty in predictions of the climate response to rising levels of greenhouse gases Nature, 433, 403-6.

23. Stockdale, T.N. 1997: Coupled Ocean-Atmosphere Forecasts in the Presence of Climate Drift. Monthly Weather Review, 125, 809-818 doi:10.1175/15200493(1997)125<2520:CSOAWD>2.0.CO;2.

24. Stockdale, T.N., Anderson, DLT, Balmaseda, M, Doblas Reyes, F, Ferranti, L, Mogensen, K, Molteni, F. \& Vitart F. 2010: ECMWF Seasonal Forecast System 3 and its prediction of Sea Surface Temperature. Clim. Dyn. Doi: 10.1007/s00382-010-0947-3.

25. Hamill, T.M. \& Hagedorn, R. 2007: Exploring ensemble forecast calibration issues using reforecast data sets. ECMWF Workshop on Ensemble Prediction, 7 - 9 November 2007, 185-199. 
26. Palmer, T. (2006) Predictability of weather and climate: from theory to practice. In Predictability of Weather and Climate, Ed T N Palmer and R Hagedorn, CUP.

27. Balmaseda, M. \&Anderson, D. 2009: Impact of initialization strategies and observations on seasonal forecast skill, Geophys. Res. Lett., 36, L01701, doi:10.1029/2008GL035561.

28. Davey, MK \& 22 others 2002: STOIC: a study of coupled model climatology and variability in tropical ocean regions. Climate Dynamics 18: 403 \pm 420 doi:10.1007/s00382-001-0188-6 (2009).

29. Stockdale, TN, Balmaseda, M. \& Vidard, A. (2006) Tropical Atlantic SST Prediction with Coupled Ocean Atmosphere GCMs. Journal of Climate 19 (23): 6047.

30. Uppala et al. (2005), The ERA-40 re-analysis. Quart. J. R. Meteorol. Soc., 131, 2961-3012. doi: 10.1256/qj.04.176.

31. Trenberth, K. \& Co-Authors (2010). "Atmospheric Reanalyses: A Major Resource for Ocean Product Development and Modeling" in these proceedings (Vol. 2), doi:10.5270/OceanObs09.cwp.90.

32. Balmaseda, M. \& Weaver, A Heat and salt intercomparison. http://www.clivar.com/data/synthesis/intercomparison. php

33. Stammer, D. \& Co-Authors (2010). "Ocean Information Provided Through Ensemble Ocean Syntheses" in these proceedings (Vol. 2), doi:10.5270/OceanObs09.cwp.85.

34. Anderson, D.L.T., Doblas-Reyes, F.J., Balmaseda, M. \& Weisheimer, A. 2009: Decadal variability: processes, predictability and prediction. ECMWF Tech Memo 591. Available from ecmwf.int/publications/library. http://www.ecmwf.int/publications/library/do/reference s/show?id=89132

35. Hurrell, J. \& Co-Authors (2010). "Decadal Climate Prediction: Opportunities and Challenges" in these proceedings (Vol. 2), doi:10.5270/OceanObs09.cwp.45.

36. Garzoli, S. \& Co-Authors (2010). "Progressing Towards Global Sustained Deep Ocean Observations" in these proceedings (Vol. 2), doi:10.5270/OceanObs09.cwp.34.

37. Webster, P. J., Moore, A,. Loschnigg J. \& Leban, M.: 1999: Coupled ocean-atmosphere dynamics in the Indian Ocean during 1997-98. Nature, 40, 23 September, 1999, 356-360.

38. Saji, N.H., Goswami, B.N., Vinayachandran, P.N., Yamagata, T. 1999: A dipole mode in the tropical Indian Ocean. Nature, 401, 360-363.

39. Hagedorn, R., Doblas-Reyes, F \& Palmer T. 2006: DEMETER and the application of seasonal forecasts. In Predictability of Weather and Climate, Ed T N Palmer and R Hagedorn, CUP pp702.

40. Webster, P.J. et al 2006: A three-tier overlapping prediction scheme: tools for strategic and tactical decisions in the developing world. In Predictability of Weather and Climate, Ed T N Palmer and R Hagedorn, CUP pp702.

41. Richardson, D. 2006: Predictability and economic value. In Predictability of Weather and Climate, Ed T N Palmer and R Hagedorn, CUP pp702.

42. Davey, M.K. et al 2006: Multi-model multi-method multi-decadal ocean analyses from the ENACT project. Clivar Exchanges No 38, Vol 11, no 3, July 2006.

43. Alves, O., M. Balmaseda, D. Anderson and T. Stockdale, 2004: Sensitivity of dynamical seasonal forecasts to ocean initial conditions. Quarterly Journal Roy Met Soc130, 647-668 2004

44. Balmaseda, M. \& Co-Authors (2010). "Initialization for Seasonal and Decadal Forecasts" in these proceedings (Vol. 2), doi:10.5270/OceanObs09.cwp.02.

45. Gibson et al ECMWF ERA-15 report. Available from: http://badc.nerc.ac.uk/data/ecmwf-era/era-15_doc.pdf

46. Palmer, T.N. \& 24 others 2004: Development of a European multimodel ensemble system for seasonal-tointerannual prediction (DEMETER). Bulletin of the American Met Soc, 85, 853-872. 